\title{
Determination of nasal carriage and skin colonization, antimicrobial susceptibility and genetic relatedness of Staphylococcus aureus isolated from patients with atopic dermatitis in Szczecin, Poland
}

\author{
Helena Masiuk*, Aleksandra Wcisłek and Joanna Jursa-Kulesza
}

\begin{abstract}
Background: Atopic dermatitis (AD) is one of the most frequent chronic and inflammatory skin condition. $A D$ is characterized by damaged epidermal barrier, xerosis and pruritus of eczematous skin lesions which tend to flare. The duration and frequency of exacerbation of $A D$ symptoms markedly affects the quality of patient life. AD results from the interplay between host genetics, immunity, and environmental factors, however the detailed pathogenesis of this disease is still not entirely cleared. Furthermore, disturbances of the skin microbiota and skin functional impairment predispose to secondary skin infections. Staphylococcus aureus colonizes skin and mucous membranes of 20 to $80 \%$ of healthy individuals and of $90 \%$ of patients with AD in whom this bacterium is accounted as an important $A D$ exacerbating factor. It is also proven, that $S$. aureus nasal carriage significantly increases the risk for self-transmission and endogenous infection. In the current study the presence of $S$. aureus either in nasal vestibule and on lesioned skin of 64 patients with AD enrolled in 10-year autovaccination program was determined. The genetic relatedness of $86 \mathrm{~S}$. aureus isolated from patients nose and skin using Pulsed Field Gel Electrophoresis (PFGE) and antimicrobial susceptibility of all strains to methicillin, erythromycin, clindamycin, mupirocin, gentamicin, amikacin, tetracycline, chloramphenicol and cotrimoxazole was also evaluated.
\end{abstract}

Results: In total 23 PFGE genotypes and 24 unique patterns were distinguished. 34 patients were $S$. aureus nasal carriers. Simultaneous presence of S. aureus in nose and on affected skin was found in 16 carriers colonized by indistinguishable or potentially related $S$. aureus vs 2 carriers colonized with non-related $S$. aureus in nasal vestibule and on skin.

4 isolates were methicillin resistant (MRSA) among which 3 showed constitutive MLSB resistance phenotype and remaining one was resistant to tetracycline and chloramphenicol.

In 4 isolates inducible MLSB resistance phenotype was found, one of them was additionally resistant to tetracycline. 7S. aureus were mupirocin resistant among them 3 - isolated from one patient, were resistant simultaneously to tetracyclines and chloramphenicol. 7 strains demonstrated resistance to chloramphenicol and susceptibility to all tested antimicrobial agents. The susceptibility to gentamicin, amikacin and cotrimoxazole among all examined $\mathrm{S}$.

\footnotetext{
*Correspondence: h.masiuk@op.pl

Independent Laboratory of Medical Microbiology, Pomeranian Medical

University, al. Powstańców Wielkopolskich 72, 70-111 Szczecin, Poland

(c) The Author(s). 2021 Open Access This article is licensed under a Creative Commons Attribution 4.0 International License, which permits use, sharing, adaptation, distribution and reproduction in any medium or format, as long as you give appropriate credit to the original author(s) and the source, provide a link to the Creative Commons licence, and indicate if changes were made. The images or other third party material in this article are included in the article's Creative Commons licence, unless indicated otherwise in a credit line to the material. If material is not included in the article's Creative Commons licence and your intended use is not permitted by statutory regulation or exceeds the permitted use, you will need to obtain permission directly from the copyright holder. To view a copy of this licence, visit http://creativecommons.org/licenses/by/4.0/. The Creative Commons Public Domain Dedication waiver (http://creativecommons.org/publicdomain/zero/1.0/) applies to the data made available in this article, unless otherwise stated in a credit line to the data.
} 


\section{aureus was confirmed.}

Conclusion: The obtained results indicated non-clonal structure of S. aureus circulating in AD patients. PFGE results showed the clonal-structure of vast majority of S. aureus isolated from nose and skin from nasal carriers what may prove the autoinfection in these patients. All examined patients the moderate or strong severity of AD was reported. Susceptibility to most antibiotics among isolated strains was also observed.

Keywords: Staphylococcus aureus, Atopic dermatitis, Skin and soft tissue infections, Nasal carriage

\section{Background}

Atopic dermatitis - AD (also called atopic eczema $\mathrm{AE}$ ) is a long - standing inflammatory dermatosis characterized by intense itching of affected skin and recurrence of chronic eczematous lesions [1]. In adult patients AD mainly manifests with lesions localized mostly on face and neck, and in up to $30 \%$ of these patients the hand atopic eczema is determined [2].

The multifactorial pathogenesis of AD includes altered immune response, several genetic predispositions and environmental factors which along with epidermal barrier dysfunctions significantly impair the functional integrity of the skin [3]. During flares of the disease the disturbances of skin microbial composition and also other skin barrier defects consequently contribute to exacerbation of AD symptoms [1].

Staphylococcus aureus (S. aureus) is the major pathogenic bacterium which activity is closely associated with severity and the course of the AD [4]. Although, S. aureus is present on skin and mucous membranes of healthy individuals and remains in balance with the host, its overgrowth is most probably linked to the reduced number of skin microbiota representatives on affected skin normally inhibiting activity of this bacterium. Nevertheless, some authors have suggested, that composition of the whole skin microbiome correlates with the course of AD and exacerbation of its symptoms [57]. S. aureus isolated from individuals with AD demonstrates enhanced ability to adhere to corneocytes and produces toxins and enzymes contributing to the exacerbation of disease symptoms [8].

Higher rates of $S$. aureus nasal colonization, strongly linked with the duration and severity of AD have been observed in patients with AD. Moreover, patients persistently colonized by $S$. aureus in nose are more prone to skin and soft tissue infections (SSTIs), and therefore experience more often the AD symptoms worsening [9-12].

In the current study the relatedness of $86 \mathrm{~S}$. aureus isolated from nose and skin of patients with atopic dermatitis was determined with the special regard to genetic relatedness of strains from nose and skin in $S$. aureus nasal carriers. Obtained results indicate the autoinfection with $S$. aureus in nasal-carriers. The results of antimicrobial susceptibility test proved the good susceptibility in vast majority of strains to antimicrobial drugs recommended for treating $\mathrm{AD}$ complicated by $S$. aureus presence.

\section{Methods}

The aim of the study was to determine the genetic relatedness of $86 \mathrm{~S}$. aureus strains isolated from affected skin and nose of 64 non-related patients with $\mathrm{AD}$ and to determine the susceptibility of isolated strains to antimicrobial agents.

\section{Study population}

A total of 64 non-related patients with chronic AD were enrolled in the study. Eligibility for the autovaccination program is voluntary but patients must meet certain criteria including the diagnosis of AD made by a dermatologist. A referral for an autovaccine from dermatologist is an absolute requirement. The diagnosis is based i.a. on physical examination and includes The assessment of AD severity is scored by dermatologist in accordance with SCORAD (Scoring Atopic Dermatitis) index. The duration, severity of the $\mathrm{AD}$ and frequency of the disease exacerbations is also evaluated. The first indication for a patient to undergo autovaccine therapy is the chronicity of the disease and documented unsatisfactory effectiveness of all previous forms of treatment. In all patients included in the study the AD was considered as the lifelong chronic condition. In all patients the previous treatment with antihistamines, corticosteroids and topical anti-inflammatory preparations was reported.

An autovaccine, called also autologous vaccine, is derived from an inactivated bacterial strain considered as an etiological agent of the infection and intended for use just by the patient from whom the strain was isolated. The intention of autovaccination used in therapy of $\mathrm{AD}$ is to stimulate or modulate innate and specific immune response against the $S$. aureus and therefore to relieve the AD symptoms [13]. The preparation of autologous vaccines is described in previously published work [14].

Prior the collection of specimens the data concerning the existence of any hypersensitivity/conditions from all patients were collected. All patients were also asked to rate the severity of $\mathrm{AD}$ exacerbation at the moment of 
collection and to evaluate the frequency of exacerbation episodes in previous 6 months. No other data were collected.

The nasal carriage screening allowed to divide examined symptomatic AD patients into 3 groups: nasal carriers with skin actually affected with S. aureus (group I 18 patients -40 strains), nasal carriers with skin actually not affected with S. aureus (group II - 16 patients - 16 strains) and nasal non - carriers with skin actually affected with S. aureus (group III - 30 patients - 30 strains).

The median age of patients was 43 years. Females accounted for $57,8 \%(37 / 64)$ vs for $42,2 \%$ (27/64) of males. All patients manifested the exacerbations of $\mathrm{AD}$ symptoms when conducting the examination.

\section{Bacterial strains}

Specimen collection and identification of the microorganism was performed in accordance to the routine microbiological diagnostics procedures. To determine the presence of $S$. aureus, a swab from affected skin and from nose of every patient were obtained. Specimen was collected from each patient from the actually most inflamed skin site. All swabs were cultured onto Columbia Agar with 5\% of sheep blood (bioMerieux, France) and Mannitol - Salt Agar (bioMerieux, France) and incubated for $18 \mathrm{~h}$ in $37^{\circ} \mathrm{C}$. Determination of $S$. aureus species was performed on the basis of ability to ferment mannitol, to coagulate rabbit plasma and on biochemical properties (VITEK System, bioMerieux). The isolated strains were also subsequently used in the preparation of the autovaccines.

\section{DNA isolation}

Analysis of genetic relatedness of all investigated strains was performed using restriction of total bacterial DNA with SmaI enzyme (MBI Fermentas, Canada) and separation of restricted fragments using Pulsed Field Gel Electrophoresis (PFGE) according to protocol of Centers for Disease Control and Prevention [15] with some modifications.

After $24 \mathrm{~h}$ of incubation on Columbia Agar with $5 \%$ of sheep blood (bioMerieux, France) a single colony of each analyzed strain was transferred to $10 \mathrm{ml}$ of Tryptic Soy Broth (TSB) liquid medium and incubated overnight with shaking at $37^{\circ} \mathrm{C}$. After incubation, $90 \mu \mathrm{l}$ of each culture was centrifuged in $2 \mathrm{ml}$ Eppendorf Tube (Eppi) at $12.000 \mathrm{x}$ g for $2 \mathrm{~min}$ in room temperature (RT). After discarding the supernatant bacterial pellet was resuspended in $300 \mu \mathrm{l}$ TE buffer ( $10 \mathrm{mM}$ TRIS, $1 \mathrm{mM}$ EDTA, $\mathrm{pH} 8,0)$ and incubated in water bath at $37^{\circ} \mathrm{C}$ for $10 \mathrm{~min}$. Next, $4 \mu \mathrm{l}$ of lysostaphin (stock solution $1 \mathrm{mg} / \mathrm{ml}, 20 \mathrm{mM}$ sodium acetate, $\mathrm{pH} 4,5$; Sigma Aldrich, Germany) and $10 \mu \mathrm{l}$ of lysozyme (DNA, Gdańsk, Poland) were added.
Simultaneously, $1 \mathrm{ml}$ of $2 \%$ agarose previously preheated to $55^{\circ} \mathrm{C}$ was added to each sample, pipetted, and immediately transferred using spatula into plug molds. Samples were left to solidify at RT. Next, agarose plugs were transferred into $2 \mathrm{ml}$ Eppi containing $1 \mathrm{ml} \mathrm{EC} \mathrm{buffer} \mathrm{(6}$ $\mathrm{mM}$ TRIS $\mathrm{HCl}, 1 \mathrm{M} \mathrm{NaCl}, 100 \mathrm{mM}$ EDTA, 0,5\% Brij-58, 0,2\% sodium deoxycholate, $0,5 \%$ sodium lauroyl sarcosinate), $25 \mu \mathrm{l}$ of Proteinase K (DNA, Gdańsk, Poland) and $4 \mu \mathrm{l}$ of lysostaphin (stock solution $1 \mathrm{mg} / \mathrm{ml}, 20 \mathrm{mM}$ sodium acetate, $\mathrm{pH} 4,5$; Sigma Aldrich, Germany). The mixture was incubated in water bath at $37^{\circ} \mathrm{C}$ for $24 \mathrm{~h}$, washed 4 times with TE buffer $(10 \mathrm{mM}$ TRIS, $1 \mathrm{mM}$ EDTA, pH 8,0) in RT and stored in TE buffer at $4{ }^{\circ} \mathrm{C}$ till restriction digestion.

\section{Restriction digestion}

Each plug was removed from Eppi using a spatula and placed on a sterile Petri dish. A slice of plug to desire comb size was cut using scalpel, placed in 1,5 ml Eppi containing $500 \mu \mathrm{l}$ buffer - water mixture (MBI Fermentas, Canada) (10X Buffer Tango stock diluted 1:10 with sterile type I water) and incubated at RT for $30 \mathrm{~min}$. After equilibration the buffer - water mixture was removed by aspirating the buffer with pipet and $300 \mu \mathrm{l}$ of buffer - water mixture with $3 \mu \mathrm{l}$ of SmaI enzyme were added. The samples were mixed by gently tapping the tubes and incubated in water bath at $30^{\circ} \mathrm{C}$ for $24 \mathrm{~h}$. After incubation all samples were washed 3 times with TE buffer. Meanwhile, the TBE (Tris/Borate/EDTA) buffer (Inno - Train Diagnostik GmbH, Germany) and 1\% agarose gel were prepared. Enzymatically digested plug slices were loaded into agarose gel wells and two standards were loaded into first and the last well (BioLine, England). The samples were electrophoresed using CHEF - DR apparatus (Bio - Rad Laboratories, France). The parameters were set as follows: run time $-20 \mathrm{~h}$, initial switch time of $5 \mathrm{~s}$ and final switch time of $40 \mathrm{~s}$, temperature at $14{ }^{\circ} \mathrm{C}$, voltage at $6 \mathrm{~V} / \mathrm{cm}$ and the included angle at $120^{\circ} \mathrm{C}$. After running, the gel was stained with ethidium bromide water solution (1:10 with distilled water) in a covered container for $20-30 \mathrm{~min}$. The gel was distained in fresh distilled water 2 times.

\section{PFGE fingerprints analysis}

The gel was visualized under UV light and documented using Quantity One (Bio - Rad Laboratories, France). Digital images were analyzed with FPQuest Software 4.5 (Bio - Rad Laboratories, France). The dendrogram was generated using the Dice correlation coefficient and the unweighted pair group method with arithmetic mean with $1 \%$ tolerance and $1 \%$ of band position. PFGE band patterns with $\geq 72 \%$ were considered and clonally related (cut off point $-\mathrm{Sab}=72 \%$ ). 


\section{Antimicrobial susceptibility test}

The disc diffusion method was performed on MuellerHinton agar plates (bioMerieux) with following antibiotic paper discs - disc content $(\mu \mathrm{g})$ : cefoxitin $(30 \mu \mathrm{g})$, erythromycin $(15 \mu \mathrm{g})$, clindamycin $(2 \mu \mathrm{g})$, mupirocin $(10 \mu \mathrm{g})$, gentamicin $(10 \mu \mathrm{g})$, amikacin $(10 \mu \mathrm{g})$, tetracycline $(30 \mu \mathrm{g})$, chloramphenicol $(30 \mu \mathrm{g})$, trimethoprim/ sulfamethoxazole (cotrimoxazole) $(1.25 / 23.75 \mu \mathrm{g})$, (Becton Dickinson, USA). Tests were performed and interpreted according to the guidelines of the European Committee of Antimicrobial Susceptibility Testing (EUCAST) [16].

\section{Results}

PFGE results

The genetic relatedness of strains isolated simultaneously from affected skin and from nose of $S$. aureus carriers (group I), as well as relatedness of all $S$. aureus isolates were determined. Examined $S$. aureus represented 23 PFGE genotypes (clusters denoted with the letters from $\mathrm{A}-\mathrm{T}$ and $\mathrm{V}-\mathrm{X}$ ) and 24 unique PFGE genotypes (denoted with the letter $\mathrm{U}$ ).

Patients from group I and group II were nasal carriers of $S$. aureus (34 patients in total). In $16 S$. aureus carriers (group I) colonization of affected skin with indistinguishable or potentially related strains was found. In two patients from group I S. aureus isolated from nose and skin showed no genetic relatedness and represented different PFGE types. Strains isolated from skin and nose of patients from group I within each pair shared the same antibiotic susceptibility patterns. The genetic relatedness analysis was performed in accordance to Tenover's guidelines [17]. Dendrogram representing PFGE genotypes is shown in Fig. 1.

\section{Antimicrobial susceptibility test}

In total 86 strains of $S$. aureus from 64 patients with atopic dermatitis were tested for antimicrobial drug resistance. 59 isolates $(59 / 86)$ were susceptible to all tested antimicrobial agents. Methicillin resistance (MRSA) was confirmed in 4 strains. Among MRSA 3 strains showed the presence of constitutive MLSB (MLSBc) and one was simultaneously resistant to tetracycline and chloramphenicol. In 4 strains inducible MLSB (MLSBi) was confirmed and one of them was resistant to tetracycline. Mupirocin resistance was confirmed in 7 strains among them 3 demonstrated resistance to tetracycline and chloramphenicol (all 3 were isolated from one patient). Resistance to chloramphenicol and susceptibility to other antimicrobial agents was found in 7 strains, resistance only to tetracycline in 5 strains (isolated from one patient). The susceptibility to gentamicin, amikacin and cotrimoxazole among all examined $S$. aureus was confirmed. Distribution of resistance phenotypes among S. aureus is shown in Fig. 1.

\section{Disscussion}

The course of atopic dermatitis (AD), an inflammatory skin condition, associated with type I allergic diseases is strongly influenced by a complex of variety of factors such as individual genetic and immunological predispositions, impaired skin barrier function and environment. All these taken together exacerbate $\mathrm{AD}$ symptoms from moderate to severe [18], nevertheless the detailed pathophysiology of $\mathrm{AD}$ still remains unclear. It is worth to note, that $\mathrm{AD}$ has an age-dependent distribution and affects around $20 \%$ of children worldwide. In $90 \%$ of patients $\mathrm{AD}$ begins from an early age, what is most probably associated with higher rates of skin colonization by S. aureus in children [19] and in $10 \%$ of AD patients it may persist for life [20].

Human skin microbiota is represented by a wide range of microorganisms which coexistence and integrity prevents skin from bacterial invasion. Most of the microorganisms reside on the skin in asymptomatic manner, among them also S. aureus which constitutes an integral part of skin microbiome in around 30\% human population representatives [21]. It is worth emphasizing that less diverse skin microbiome, observed in patients with $\mathrm{AD}$, may predispose to $S$. aureus overgrowth [22]. Lesional skin colonization by $S$. aureus is commonly observed in $\mathrm{AD}$ patients however, colonization may also indicate non-lesional skin [23-25]. It has been demonstrated that the progression and severity of $\mathrm{AD}$ are closely related with the ability of $S$. aureus to penetrate through skin barrier what stimulates the immune response leading to the persistent skin inflammation [22]. Dehydrated and thinner skin of AD patients is much more vulnerable to injury and therefore to infection and irritation by allergens [26]. Celakovska and Bukac $[27,28]$ observed the significant relation between the severity of $\mathrm{AD}$ and sensitization mites, animal dander, dust of feather. According to authors observation patients with strong or moderate form of $A D$ suffer more often from sensitization to aboved factors. In the present study 22 patients declared the contact dermatitis, 16 patients declared the allergic rhinitis (AR) and 2 patients declared the diagnosed bronchial asthma (BA). Among them 7 (with AR) and 1 (with BA) described the severity as strong. The obtained results seem to support the observation of the authors.

In comparison performed by Simpson et al. AD patients colonized with $S$. aureus more often experience severe course of AD than non-colonized individuals and demonstrate the elevated levels of IgE and eosinophils in serum. Furthermore, the skin barrier of S. aureus colonized patients is significantly impaired with enhanced 


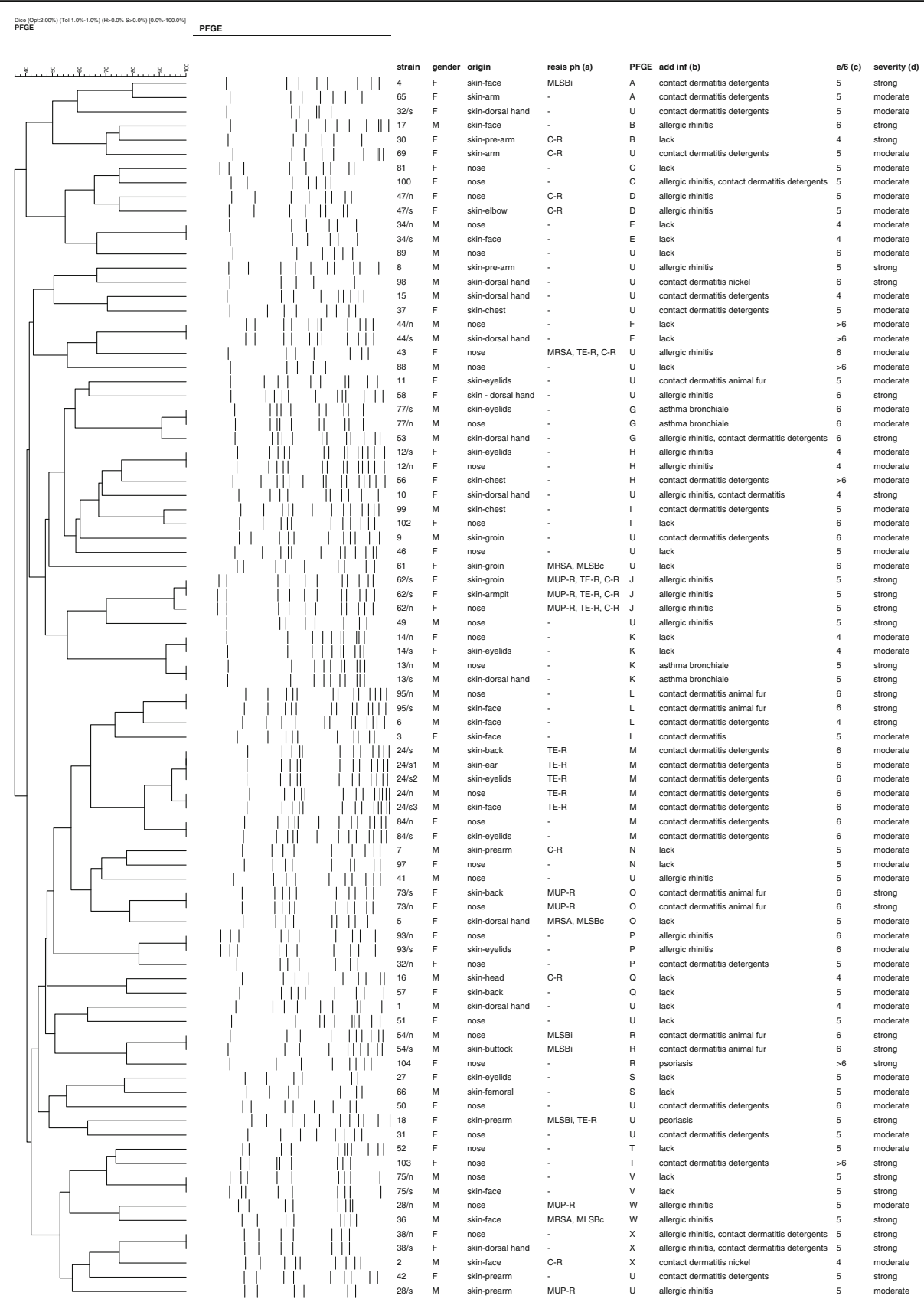

Fig. 1 Dendrogram representing the relatedness of $86 \mathrm{~S}$. aureus isolated from affected skin and from nose of 64 patients with AD. (Cut-off point 72.0 (Dice), resistance phenotypes of all examined S. aureus and additional patient's data. The clusters were marked with the letters A-T and V-X, and the unique genotypes were marked with the letter U. Patient/s skin isolate, patient/ $\mathrm{n}$ - nose isolate. F-female, M-male. (a) - resistance phenotypes - MRSA-methicillin resistant Staphylococcus aureus, MLSB-macrolide, lincosamide and streptogramin B resistant (MLSBc-constitutive, MLSBi-inducible), MUP-R - mupirocin resistant, TE-R- tetracycline resistant, C-R - chloramphenicol resistant. (b) additional data concerning the concomitant conditions in examined patients include psoriasis, bronchial asthma, allergic rhinitis, contact dermatitis. Lack - patients who denied the existence of hypersensitivity/conditions. (c) number of flares in previous 6 months. (d) - exacerbations classified as moderate or strong based on the patients personal rating

expression of adhesive molecules and increased permability what made skin much more prone to be colonized [29]. In our study patients were asked to evaluate the grade the intensity of $\mathrm{AD}$ flares at the moment of specimen collection. What is interesting, the severity of $\mathrm{AD}$ exacerbations described as "strong" was declared by 7 patients from group I vs 11 who declared the severity of AD flares ass "moderate" (39\%). "Strong severity of 
AD was declared by $19 \%$ and $25 \%$ of patients from group II and group III respectively. None of the patients declared the AD severity as "mild". The above results seem to be consistent with Alsterholm et al. [30] and Ogonowska et al. who observed, that especially persistent nasal $S$. aureus carriers expierience more severe AD according to SCORAD system [31]. Its worth mentioning, that the present study evaluation of nasal carriage was performed ones for each patient, therefore in group III of patients (nasal non-carriers) intermittent nasal carriage cannot be certainly excluded. To support the management of $\mathrm{AD}$ it would be appropriate to consider nasal colonization screening performed periodically in these group of patients.

Patients examined in the present study were also asked to rate the frequency of flares in previous 6 months. None of the patients declared less than 4 episodes. Patients from group $I$ with strong form of AD declared the frequency as 5-6 episodes. Ogonowska et al., [31] observed, that the concomitant nasal and skin colonization in $\mathrm{AD}$ patients is comparatively high and nasal vestibule is considered as the potential reservoir of S. aureus, contributing to the recolonization of skin.

The nasal vestibule constitutes the reservoir of $S$. aureus, from which it spreads to other body sites and may cause multiple autoinfections [32, 33]. It is estimated, that $20-30 \%$ of healthy population representatives are persistent carriers of this bacterium [34]. The percentage of $S$. aureus carriers is higher among people with AD (38-82\%) compared to healthy individuals (10-45\%). In the current study nasal carriers constituted more than a half $(53,1 \%)$ of the of examined patients (34/64) and them in $18(18 / 34)$ the simultaneous presence of $S$. aureus on skin was confirmed. Breuer et al. isolated $S$. aureus from $94 \%$ of people with AD: from $11 \%$ exclusively from the skin, from $6 \%$ only from the nose, and from $77 \%$ from affected skin and nasal vestibule [35].

Nose (nasal vestibule) of most people with SSTI's is commonly colonized with indistinguishable, closely or potentially related $S$. aureus [35]. Phage typing and serotyping results performed by Namura et al. and Hoeger et al. revealed significant similarities between $S$. aureus strains isolated from cutaneous lesions and nasal vestibule in $64 \%$ (7 out of 11) adult patients with AD and in $73 \%$ (30 out of 41 ) children with AD respectively [36, 37]. Hoeger et al. demonstrated also the presence of indistinguishable $S$. aureus isolated from affected skin and from nasal vestibule of children with $\mathrm{AD}$ and isolated from their mothers (in $38 \%$ of cases - 22 out of 58) [37]. Pascolini et al. evaluated the risk of transmission of the $S$. aureus colonizing nasal vestibule to the other skin sites of the same patient with using the PFGE technique to determine the relatedness of analyzed strains. All 47 strains isolated from cutaneous lesions were genetically related to the strains isolated simultaneously from nose [38]. Detailed analysis of S. aureus isolated from colonized individuals sharing the same habitat and remaining in close contact with patients with AD proved, that $S$. aureus easily transmits between those individuals contributing a carrier state [35, 39, 40]. Similar PFGE findings were observed by Bonness et al. who confirmed the relatedness of $S$. aureus isolated from nose and skin in $73 \%$ (11 out of 15 ) of patients with $\mathrm{AD}$ and suggested, that significant similarities between PFGE patterns of $S$. aureus isolated from AD patients and their family members may prove the recolonization with $S$. aureus as intra - familial transmission of $S$. aureus. The $S$. aureus skin recolonization may be associated with the pathogen maintaining the carrier state in the vestibule of the nose [41]. PFGE results obtained in our study demonstrated that skin and nasal vestibule were colonized with indistinguishable strains in $16(16 / 18)$ of examined patients and in $2(2 / 18)$ with non- related $S$. aureus. The results showed also non-clonal structure of $S$. aureus isolated from affected skin of patients with $\mathrm{AD}$ and also the lack of predominating genetic type of $S$. aureus infecting patients with $\mathrm{AD}$ in West Pomeranian region. It's worth mentioning, that all patients examined in current study were during the targeted antimicrobial therapy without the implemented nasal decolonization procedures. Therefore, the recurrent exacerbations of AD symptoms were most probably associated with autoinfection with $S$. aureus in these patients.

In the current study isolated $S$. aureus showed the low rates of antimicrobial resistance to examined agents. Although an increasing rates of methicillin resistant Staphylococcus aureus (MRSA) colonizing outpatients are reported worldwide [42, 43] reaching approximately $7 \%$ within the total population, the skin of outpatients with $\mathrm{AD}$ is most frequently affected with methicillin susceptible Staphylococcus aureus (MSSA). Data concerning the rates of $\mathrm{AD}$ patients colonized with MRSA vary. Kędzierska et al. among $76 \mathrm{~S}$. aureus isolated from patients with $\mathrm{AD}$ determined the resistance to methicillin only in one strain isolated from 9-year old boy with history of hospitalization and prolonged antibiotic therapy [44]. Low rates of MRSA was also confirmed by Niehbuhr et al. who determined the presence of methicillin resistance only in 3\% of analyzed S. aureus isolated from AD patients [45]. Pascolini et al. among $113 \mathrm{~S}$. aureus isolated from carriers and from their infected skin found the presence of methicillin resistance in 9 strains $(7,9 \%)$ of which 6 were isolated from skin lesions [38]. In studies conducted by Hoeger et al. and L.S. Chiu et al. the lack of MRSA was confirmed among all tested strains isolated from $\operatorname{AD}[37,46]$. Nevertheless, Ching - Shen Tang et al. demonstrated as many as $30,8 \%$ of MRSA colonizing skin of 78 healthy children with AD and $60 \%$ 
of MRSA infecting skin of 20 children with AD. High percentage of MRSA colonizing different body sites in patients with $\mathrm{AD}$ is most probably closely associated with the selection of MRSA following prior therapy with beta-lactams [47]. It is worth remembering, that skin colonization with MRSA also follows previous hospitalization increasing the likelihood of contact with hospital strains [48] or may be associated with the direct contact and transmission of MRSA within community. In the present study all examined patients denied hospitalization within 6 months before specimen collection, were also neither related nor shared the same habitat, therefore the low rates of MRSA within the patients examined in the present study seem to support the above observation.

In the study the susceptibility to erythromycin and clindamycin of investigated $S$. aureus was also determined. MLSB - the acquired resistance to macrolides, lincosamides and streptogramin B results from the decreased binding of these antibiotics to the methylated 50S ribosomal subunit, an overlapping binding site for all three groups of antimicrobial agents [49]. Constitutive MLSB (MLSBc) phenotype is associated with the rRNA methylase constantly produced by the bacterial strain, whereas in the bacteria with inducible MLSB (MLSBi) the production of methylase is observed in the presence of an inducing agent [50]. The D-test method is reccomended to determine the inducible MLSB, due to fact that this type of resistance cannot be determined with standard susceptibility tests. D-test reveals the inducible resistance to clindamycin (MLSBi) when disc with clindamycin is placed in close proximity to erythromycin disc and D-shaped inhibited growth zone is flattened between erythromycin and clindamycin. This method allows to avoid the clinical failures of treatment with clindamycin the infections caused by MLSBi strains and to distinguish the MLSBi from MS phenotype strains resistant to erythromycin and streptogramin B but susceptible to clindamycin [51]. The importance of the proper determination MLSB phenotype is worth to underline, since clindamycin is recommended to treat uncomplicated skin and soft tissue infections, particularly an alternative for the treatment of infections caused by MRSA [52].

MLSB resistance phenotype was confirmed in 7 strains,among them 3 simultaneously showed methicillin resistance. Concomitant resistance to beta-lactams, macrolides and lincosamides significantly compromises therapy leaving not many treatment options for therapy in community [53-55].

Although topical skin decolonization with antimicrobial agents may reduce the risk of subsequent SSTI's [34, 35] and may be an important element of medical strategy in patients with AD. However Polish Society of
Atopic Diseases does not recommend the prolonged topical use of antibiotics and oral antimicrobial therapy, short courses of oral antibiotics, such as cephalosporins, may be implemented in patients with clinical signs of bacterial infection. Other studies have shown that treatment with oral flucloxacillin or cefuroxime caused a significant reduction in $S$. aureus skin colonization in children. However no significant relief of AD symptoms was observed. Soon after the treatment, recolonization with S. aureus was observed [56] and exacerbation of AD symptoms were assumed [57]. Prolonged antimicrobial treatment entails also the risk of adverse effects such as skin microbiota disruption, contact dermatitis or selection of resistant bacteria, including MRSA.

Due to the fact that oral antimicrobial agents poorly penetrate the nasal mucosa, an oral treatment with topical application of mupirocin may be an improvement of carrier state eradication outcomes [12]. In the present study vast majority of examined strains isolated from nasal vestibule (79/86) showed susceptibility to mupirocin and the obtained result is close to ones obtained for S. aureus isolated from patients in Europe (6,6\%) [58]. Mupirocin has been approved for eradication of MRSA and MSSA nasal carriage, however, the increasing prevalence of resistance to this antimicrobial agent among $S$. aureus is observed worldwide. In our study the lack of methicillin resistance in mupirocin resistant isolates was confirmed. Therefore overuse or uncontrolled use of mupirocin may lead to increased emergence of resistant strains and hence to reduction of the likelihood of $S$. aureus successful eradication.

It's important to underline that antimicrobial therapy should be considered only in exacerbation of AD symptoms and complications following multiple and recurrent bacterial skin infections. The immunization with autovaccines composed of unique $S$. aureus antigens that aim the skin beneficial bacteria remain unharmed, is considered as an alternative in AD management [5961].

Consequently, management of $\mathrm{AD}$ complicated by $S$. aureus colonization should also consider the eradication of $S$. aureus from nose. With the restoration of skin structure and its function it may decrease the risk of autoinfection and the frequency of $\mathrm{AD}$ exacerbations significantly improving the severity of AD.

\section{Acknowledgements}

We would like to thank Kinga Nurczyńska for technical assistance during performing this study.

\section{Authors' contributions}

$J \mathrm{JK}$ and HM contributed to the study conception and design. Material preparation and data analysis were performed by JJK, HM and AW. The draft of the manuscript was written by JJK and HM and all authors commented on previous versions of the manuscript. All authors approved the final manuscript. 


\section{Funding}

Not applicable.

\section{Availability of data and materials}

All data generated or analysed during this study are included in this published article. Data sharing is not applicable to this article as no datasets were generated or analysed during the current study. S. aureus isolates used in the current study are the part of the collection belonging to the Independent Laboratory of Medical Microbiology, Pomeranian Medical University, Szczecin, Poland.

\section{Declarations}

\section{Ethics approval and consent to participate}

Patient data have been collected as the part of the project after obtaining permission (KB-0012/112/17) from the Bioethics Comitee of Pomeranian Medical University in Szczecin, Poland. Patient identity remained confidential. In this study informed consent for swab and strains collection was not required as the isolates examined in the current study were collected during the routine microbiological diagnostic in order to prepare the autovaccine. The raw data and samples mentioned in the methods are the property of the Independent Laboratory of Medical Microbiology, Pomeranian Medical University.

\section{Consent for publication}

Not applicable.

\section{Competing interests}

The authors declare that they have no competing interests

\section{Received: 12 February 2021 Accepted: 11 June 2021}

Published online: 23 July 2021

\section{References}

1. Kim J, Kim H. Microbiome of the skin and gut in atopic dermatitis (AD): understanding the pathophysiology and finding novel management strategies. J Clin Med. 2019;8(4):444. https://doi.org/10.3390/jcm8040444.

2. Thomsen SF. Atopic dermatitis: natural history, diagnosis, and treatment. ISRN Allergy. 2014;2014:1-7. https://doi.org/10.1155/2014/354250.

3. Levin J, Friedlander SF, Del Rosso JQ. Atopic dermatitis and the stratum corneum: part 1: the role of filaggrin in the stratum corneum barrier and atopic skin. J Clin Aesthet Dermatol. 2013;6(10):16-22. http://www.ncbi.nlm. nih.gov/pubmed/24155988.

4. Iwamoto K, Moriwaki M, Miyake R, Hide M. Staphylococcus aureus in atopic dermatitis: strain-specific cell wall proteins and skin immunity. Allergol Int. 2019;68(3):309-15. https://doi.org/10.1016/J.ALIT.2019.02.006.

5. Lynde CW, Andriessen A, Bertucci V, McCuaig C, Skotnicki S, Weinstein M, et al. The skin microbiome in atopic dermatitis and its relationship to emollients. J Cutaneous Med Surg. 2016;20(1):21-8. https://doi.org/10.11 77/1203475415605498

6. Machura E, Mazur B, Golemiec E, Pindel M, Halkiewicz F. Staphylococcus aureus skin colonization in atopic dermatitis children is associated with decreased IFN- $\gamma$ production by peripheral blood CD4 + and CD8+ T cells. Pediatr Allergy Immunol. 2008;19(1):37-45. https://doi.org/10.1111/j.1399-3 038.2007.00586.x.

7. Clausen ML, Agner T, Lilje B, Edslev SM, Johannesen TB, Andersen PS. Association of disease severity with skin microbiome and filaggrin gene mutations in adult atopic dermatitis. JAMA Dermatol. 2018;154(3):293-300. https://doi.org/10.1001/jamadermatol.2017.5440.

8. Geoghegan JA, Irvine AD, Foster TJ. Staphylococcus aureus and atopic dermatitis: a complex and evolving relationship. Trends Microbiol. 2018; 26(6):484-97. https://doi.org/10.1016/j.tim.2017.11.008.

9. Wertheim HFL, Melles DC, Vos MC, Van Leeuwen W, Van Belkum A, Verbrugh $\mathrm{HA}$, et al. The role of nasal carriage in Staphylococcus aureus infections. Lancet Infect Dis. 2005;5(12):751-62. https://doi.org/10.1016/S14 73-3099(05)70295-4.

10. Durupt F, Mayor L, Bes M, Reverdy M-E, Vandenesch F, Thomas $L$, et al. Prevalence of Staphylococcus aureus toxins and nasal carriage in furuncles and impetigo. Br J Dermatol. 2007;157(6):1161-7. https://doi.org/10.1111/j.13 65-2133.2007.08197.x.
11. Nouwen $J$, Fieren MWJA, Snijders S, Verbrugh HA, Van Belkum A. Persistent (not intermittent) nasal carriage of Staphylococcus aureus is the determinant of CPD-related infections. Kidney Int. 2005;67(3):1084-92. https://doi.org/10.1111/j.1523-1755.2005.00174.x.

12. Sakr A, Brégeon F, Mège J-L, Rolain J-M, Blin O. Staphylococcus aureus nasal colonization: an update on mechanisms, epidemiology, risk factors, and subsequent infections. Front Microbiol. 2018;9:2419. https://doi.org/10.3389/ fmicb.2018.02419.

13. Szkaradkiewicz A, Karpiński TM, Goślińska-Pawłowska O, Szkaradkiewicz AK, Giedrys-Kalemba S. Cytokine response in autovaccine-treated patients with chronic Staphylococcus aureus infections. Eur J Inflamm. 2013;11(1):103-10. https://doi.org/10.1177/1721727X1301100110.

14. Holtfreter S, Jursa-Kulesza J, Masiuk H, Verkaik NJ, Vogel C, Kolata J, et al. Antibody responses in furunculosis patients vaccinated with autologous formalin-killed Staphylococcus aureus. Eur J Clin Microbiol Infect Dis. 2011; 30(6):707-17. https://doi.org/10.1007/s10096-010-1136-3.

15. Centers for Disease Control and Prevention (CDC). Unified PulsedField Gel Electrophoresis (PFGE) protocol for gram positive bacteria. Atlanta: Centers for Disease Control and Prevention (CDC); 2012. https://www.cdc.gov/hai/ pdfs/labsettings/unified_pfge_protocol.pdf.

16. European Committee on Antimicrobial Susceptibility Testing Breakpoint tables for interpretation of MICs and zone diameters European Committee on Antimicrobial Susceptibility Testing Breakpoint tables for interpretation of MICs and zone diameters. 2021. p. 0-77. http://www.eucast.org/filea $\mathrm{dmin} / \mathrm{src} / \mathrm{media} /$ PDFs/EUCAST_files/Breakpoint_tables/v_5.0_Breakpoint_Ta ble_01.pdf.

17. Tenover FC, Arbeit RD, Goering RV, Mickelsen PA, Murray BE, Persing DH, et al. Interpreting chromosomal DNA restriction patterns produced by pulsed- field gel electrophoresis: criteria for bacterial strain typing. J Clin Microbiol. 1995;33(9):2233-9. https://doi.org/10.1128/jcm.33.9.2233-2239.1 995.

18. Nakatsuji T, Gallo RL. The role of the skin microbiome in atopic dermatitis. Ann Allergy Asthma Immunol. 2019;122(3):263-9. https://doi.org/10.1016/j.a nai.2018.12.003.

19. Williams H, Robertson C, Stewart A, Aït-Khaled N, Anabwani G, Anderson R, et al. Worldwide variations in the prevalence of symptoms of atopic eczema in the international study of asthma and allergies in childhood. J Allergy Clin Immunol. 1999;103(1 I):125-38. https://doi.org/10.1016/S0091-674 9(99)70536-1.

20. Silverberg Jl. Public health burden and epidemiology of atopic dermatitis. Dermatol Clin. 2017;35(3):283-9. https://doi.org/10.1016/.det.2017.02.002.

21. Erin Chen $Y$, Fischbach MA, Belkaid Y. Skin microbiota-host interactions. Nature. 2018;553(7689):427-36. https://doi.org/10.1038/nature25177.

22. Niebuhr M, Gathmann M, Scharonow H, Mamerow D, Mommert S, Balaji H, et al. Staphylococcal alpha-toxin is a strong inducer of interleukin-17 in humans. Infect Immun. 2011;79(4):1615-22. https://doi.org/10.1128/IAI. 00958-10.

23. Bunikowski R, Mielke MEA, Skarabis H, Worm M, Anagnostopoulos I, Kolde $\mathrm{G}$, et al. Evidence for a disease-promoting effect of Staphylococcus aureusderived exotoxins in atopic dermatitis. J Allergy Clin Immunol. 2000;105(4): 814-9. https://doi.org/10.1067/mai.2000.105528.

24. Gong JQ, Lin L, Lin T, Hao F, Zeng FQ, Bi ZG, et al. Skin colonization by Staphylococcus aureus in patients with eczema and atopic dermatitis and relevant combined topical therapy: a double-blind multicentre randomized controlled trial. Br J Dermatol. 2006;155(4):680-7. https://doi.org/10.1111/j.13 65-2133.2006.07410x

25. Nowicka D, Grywalska E. The role of immune defects and colonization of Staphylococcus aureus in the pathogenesis of atopic dermatitis. Anal Cell Pathol. 2018;2018:1-7. https://doi.org/10.1155/2018/1956403.

26. Wang V, Boguniewicz J, Boguniewicz M, Ong PY. The infectious complications of atopic dermatitis. Ann Allergy Asthma Immunol. 2021; 126(1):3-12. https://doi.org/10.1016/j.anai.2020.08.002.

27. Čelakovská J, Bukač J, Vaňková R, Krcmova I, Krejsek J, Andrýs C. Sensitisation to molecular components in patients with atopic dermatitis, relation to asthma bronchiale and allergic rhinitis. Food Agric Immunol. 2020;31(1):600-29. https://doi.org/10.1080/09540105.2020.1747406.

28. Čelakovská J, Bukač J. Severity of atopic dermatitis in relation to food and inhalant allergy in adults and adolescents. Food Agric Immunol. 2017;28(1): 121-33. https://doi.org/10.1080/09540105.2016.1228838.

29. Simpson EL, Villarreal M, Jepson B, Rafaels N, David G, Hanifin J, et al. Patients with atopic dermatitis colonized with Staphylococcus aureus have 
a distinct phenotype and Endotype. J Invest Dermatol. 2018;138(10):222433. https://doi.org/10.1016/j.jid.2018.03.1517.

30. Alsterholm M, Strömbeck L, Ljung A, Karami N, Widjestam J, Gillstedt M, et al. Variation in Staphylococcus aureus colonization in relation to disease severity in adults with atopic dermatitis during a fivemonth follow-up. Acta Derm Venereol. 2017;97(7):802-7. https://doi.org/10.2340/00015555-2667.

31. Ogonowska P, Gilaberte Y, Barańska-Rybak W, Nakonieczna J. Colonization with Staphylococcus aureus in atopic dermatitis patients: attempts to reveal the unknown. Front Microbiol. 2021. p. 11. https://doi.org/10.3389/fmicb.202 0.567090 .

32. Coates T, Bax R, Coates A. Nasal decolonization of Staphylococcus aureus with mupirocin: strengths, weaknesses and future prospects. J Antimicrob Chemother. 2009;64(1):9-15. https://doi.org/10.1093/jac/dkp159.

33. Wertheim HFL, Walsh E, Choudhurry R, Melles DC, Boelens HAM, Miajlovic H, et al. Key role for clumping factor B in Staphylococcus aureus nasal colonization of humans. PLoS Med. 2008;5:0104-12.

34. Smith CH, Goldman RD. Staphylococcus aureus decolonization for recurrent skin and soft tissue infections in children. Can Fam Physician. 2012;58(12): 1350-2.

35. Breuer K, Häussler S, Kapp A, Werfel T. Staphylococcus aureus: colonizing features and influence of an antibacterial treatment in adults with atopic dermatitis. Br J Dermatol. 2002;147(1):55-61. https://doi.org/10.1046/j.13 65-2133.2002.04872.x.

36. Namura S, Nishijima S, Higashida T, Asada Y. Staphylococcus aureus isolated from nostril anteriors and subungual spaces of the hand: comparative study of medical staff, patients, and normal controls. J Dermatol. 1995;22(3):17580. https://doi.org/10.1111/j.1346-8138.1995.tb03366.x.

37. Hoeger PH. Antimicrobial susceptibility of skin-colonizing $\mathrm{S}$. aureus strains in children with atopic dermatitis. Pediatr Allergy Immunol. 2004;15(5):474-7. https://doi.org/10.1111/j.1399-3038.2004.00182.x.

38. Pascolini C, Sinagra J, Pecetta S, Bordignon V, De Santis A, Cilli L, et al. Molecular and immunological characterization of Staphylococcus aureus in pediatric atopic dermatitis: implications for prophylaxis and clinical management. Clin Dev Immunol. 2011;2011:1-7. https://doi.org/10.1155/2 011/718708.

39. Wenzel RP, Perl TM. The significance of nasal carriage of Staphylococcus aureus and the incidence of postoperative wound infection. J Hosp Infect. 1995;31(1):13-24. https://doi.org/10.1016/0195-6701(95)90079-9.

40. Tulloch LG. Nasal carriage in staphylococcal skin infections. Br Med J. 1954; 2(4893):912-3. https://doi.org/10.1136/bmj.2.4893.912.

41. Bonness S, Szekat C, Novak N, Bierbaum G. Pulsed-field gel electrophoresis of Staphylococcus aureus isolates from atopic patients revealing presence of similar strains in isolates from children and their parents. J Clin Microbiol. 2008:46(2):456-61. https://doi.org/10.1128/JCM.01734-07.

42. Choo EJ. Community-associated methicillin-resistant Staphylococcus aureus in nosocomial infections. Infect Chemother. 2017;49(2):158-9. https://doi. org/10.3947/ic.2017.49.2.158.

43. Bukharie H. A review of community-acquired methicillin-resistant Staphylococcus aureus for primary care physicians. J Fam Community Med. 2010;17(3):117-20. https://doi.org/10.4103/1319-1683.74320.

44. Kędzierska A, Kapińska-Mrowiecka M, Czubak-Macugowska M, Wójcik K, Kę̧dzierska J. Susceptibility testing and resistance phenotype detection in Staphylococcus aureus strains isolated from patients with atopic dermatitis, with apparent and recurrent skin colonization. Br J Dermatol. 2008;159(6): 1290-9. https://doi.org/10.1111/j.1365-2133.2008.08817.x.

45. Niebuhr M, Mai U, Kapp A, Werfel T. Antibiotic treatment of cutaneous infections with Staphylococcus aureus in patients with atopic dermatitis: current antimicrobial resistances and susceptibilities. Exp Dermatol. 2008; 17(11):953-7. https://doi.org/10.1111/j.1600-0625.2008.00734.x.

46. Chiu LS, Ho MSL, Hsu LY, Tang MBY. Prevalence and molecular characteristics of Staphylococcus aureus isolates colonizing patients with atopic dermatitis and their close contacts in Singapore. Br J Dermatol. 2009; 160(5):965-71. https://doi.org/10.1111/j.1365-2133.2009.09038.x.

47. Tang CS, Wang CC, Huang CF, Chen SJ, Tseng MH, Lo WT. Antimicrobial susceptibility of Staphylococcus aureus in children with atopic dermatitis. Pediatr Int. 2011;53(3):363-7. https://doi.org/10.1111/ j.1442-200X.2010.03227.x.

48. Ong PY. Recurrent MRSA skin infections in atopic dermatitis. J Allergy Clin Immunol Pract. 2014;2(4):396-9. https://doi.org/10.1016/j.jaip.2014.04.007.
49. Thumu SCR, Halami PM. Acquired resistance to macrolide-LincosamideStreptogramin antibiotics in lactic acid Bacteria of food origin. Indian J Microbiol. 2012;52(4):530-7. https://doi.org/10.1007/s12088-012-0296-5.

50. Leclerca R. Mechanisms of resistance to macrolides and Lincosamides: nature of the resistance elements and their clinical implications. Clin Infect Dis. 2002;34(4):482-92. https://doi.org/10.1086/324626.

51. Saderi H, Emadi B, Owlia P. Phenotypic and genotypic study of macrolide, lincosamide and streptogramin B (MLSB) resistance in clinical isolates of Staphylococcus aureus in Tehran, Iran. Med Sci Monit. 2011;17:BR48-53. https://doi.org/10.12659/msm.881386.

52. Smieja M. Current indications for the use of clindamycin: a critical review. Can J Infect Dis. 1998;9(1):22-8. https://doi.org/10.1155/1998/538090.

53. Siddiqui AH, Koirala J. Methicillin resistant Staphylococcus aureus (MRSA). 2020. http://www.ncbi.nlm.nih.gov/pubmed/29489200. Accessed 14 Sep 2020.

54. Alexander H, Paller AS, Traidl-Hoffmann C, Beck LA, De Benedetto A, Dhar S, et al. The role of bacterial skin infections in atopic dermatitis: expert statement and review from the international eczema council skin infection group. Br J Dermatol. 2020;182(6):1331-42. https://doi.org/10.1111/bjd.1 8643.

55. Daniel R. Azithromycin, erythromycin and Cloxacillin in the treatment of infections of skin and associated soft tissues. J Int Med Res. 1991;19(6):43345. https://doi.org/10.1177/030006059101900602.

56. Boguniewicz M, Leung DYM. Atopic dermatitis: a disease of altered skin barrier and immune dysregulation. Immunol Rev. 2011;242(1):233-46. https://doi.org/10.1111/j.1600-065X.2011.01027.X.

57. Huang JT, Abrams M, Tlougan B, Rademaker A, Paller AS. Treatment of Staphylococcus aureus colonization in atopic dermatitis decreases disease severity. Pediatrics. 2009;123(5):e808-14. https://doi.org/10.1542/peds.2 008-2217.

58. Dadashi M, Hajikhani B, Darban-Sarokhalil D, van Belkum A, Goudarzi M. Mupirocin resistance in Staphylococcus aureus: a systematic review and meta-analysis. J Glob Antimicrob Resist. 2020;20:238-47. https://doi.org/10.1 016/j.jgar.2019.07.032.

59. Boguniewicz M. New strategies for dealing with staphylococcus aureus colonization and the emerging methicillin-resistant staphylococcus aureus epidemic in atopic dermatitis. Chem Immunol Allergy. 2012;96:113-9. https://doi.org/10.1159/000331910.

60. Paterson MJ, Caldera J, Nguyen C, Sharma P, Castro AM, Kolar SL, et al. Harnessing antifungal immunity in pursuit of a Staphylococcus aureus vaccine strategy. PLoS Pathog. 2020;16(8):e1008733. https://doi.org/10.1371/ journal.ppat.1008733.

61. Olaniyi R, Pozzi C, Grimaldi L, Bagnoli F. Staphylococcus aureus-associated skin and soft tissue infections: anatomical localization, epidemiology, therapy and potential prophylaxis: Current Topics in Microbiology and Immunology. Springer Verlag; 2017. p. 199-227. https://doi.org/10.1007/ 82_2016_32.

\section{Publisher's Note}

Springer Nature remains neutral with regard to jurisdictional claims in published maps and institutional affiliations.

Ready to submit your research? Choose BMC and benefit from:

- fast, convenient online submission

- thorough peer review by experienced researchers in your field

- rapid publication on acceptance

- support for research data, including large and complex data types

- gold Open Access which fosters wider collaboration and increased citations

- maximum visibility for your research: over $100 \mathrm{M}$ website views per year

At BMC, research is always in progress.

Learn more biomedcentral.com/submissions 